\title{
Incidence of Helicobacter hepaticus and its relation to gallbladder carcinoma
}

\author{
Parajuli $\mathrm{S}^{1}$, Koirala $\mathrm{U}^{2}$ \\ ${ }^{1}$ Department of Pathology, Kathmandu Model Hospital, Kathmandu, Nepal \\ ${ }^{2}$ Department of Surgery, Kathmandu Model Hospital, Kathmandu, Nepal
}

\section{Keywords:}

Gallbladder carcinoma; Helicobacter hepaticus; Warthin Starry Silver stain.

\begin{abstract}
Background: Chronic cholecystitis due to cholelithiasis is one of the most common hepatobiliary surgical disorders. Bacteria are found in high concentration in bile and stone. Helicobacter hepaticus is a gram negative, micro-aerobic bacterium, curved to spiral in shape which shows positivity with urease, catalase and oxidase. Bacterial infection may be one of the causes for the pathogenesis of gallstone formation as most gallstones are colonized by a bacterial biofilm.
\end{abstract}

Materials and Methods: This was a retrospective study done in the Department of Pathology, Kathmandu Medical College for a one year period, between June 2007 and July 2008. A total of 277 cases were included in the study.

Results: Amongst the 277 cases, 270 cases (97.4\%) were diagnosed as chronic cholecystitis and 7 cases $(2.5 \%)$ were diagnosed as gallbladder carcinoma. All the cases diagnosed as gallbladder carcinoma was of adenocarcinoma except a single case of adenosquamous carcinoma. Fifty three out of the 277 cases $(19.13 \%)$ showed positivity in Warthin Starry Silver stain. Out of the 7 cases diagnosed as gallbladder carcinoma, 5 cases were found to be positive Warthin Starry Silver stain.

Conclusion: The role of Helicobacter hepaticus infection as a nidus for formation of gallstone that ultimately leads to malignancy is controversial and its dominant role in the pathogenesis of carcinoma is yet to be determined.

\section{INTRODUCTION}

Chronic cholecystitis due to cholelithiasis is one of the most common hepatobiliary surgical disorders. The incidence of cholelithiasis is 4 times higher in women than in men with high prevalence among the age group of $30-40$ years. ${ }^{1}$

The natural history of gallstone development is unknown. Bacteria are found in high concentration in bile and stone.

\footnotetext{
Correspondence:

Dr. Sharmila Parajuli, $M D$

Department of Pathology, Kathmandu Model Hospital, Kathmandu, Nepal E-mail:drsharmi@hotmail.com
}

It is difficult to say whether bacterial infection of the bile occurs before stone formation or stone formation occurs after bacterial infection. Bacterial infection may be one of the causes for the pathogenesis of gallstone formation as most gallstones are colonized by bacterial biofilm. ${ }^{2,3}$

Since the discovery of Helicobacter pylori (H. Pylori) in 1982 by Marshall and Warren, more than 25 additional Helicobacter species have been isolated. Helicobacter hepaticus (H. hepaticus) was discovered in 1992 at the National cancer institute- Fredrick Cancer Research and Development Centre and first isolated from a colony of mice, a low liver tumor incidence mouse strain with a 
Table 1: Histopathological features of cholecystectomy specimens

\begin{tabular}{|c|c|c|c|}
\hline $\mathbf{S N}$ & Diagnosis & No. of cases & Percentage \\
\hline \multicolumn{4}{|c|}{ Chronic cholecystitis $(n=270)$} \\
\hline 1. & Classic chronic cholecystitis & 164 & 59.20 \\
\hline 2. & Cholesterosis & 45 & 16.24 \\
\hline 3. & Acute on chronic cholecystitis & 23 & 8.30 \\
\hline 4. & Adenomyomatous hyperplasia & 11 & 3.97 \\
\hline 5. & Follicular cholecystitis & 9 & 3.24 \\
\hline 6. & Eosinophilic cholecystitis & 9 & 3.24 \\
\hline 7. & Intestinal metaplasia & 4 & 1.44 \\
\hline 8. & Pyloric metaplasia & 2 & 0.72 \\
\hline \multirow[t]{2}{*}{9.} & Xanthogranulomatous cholecystitis & 3 & 1.08 \\
\hline & Carcinoma $(n=7)$ & & \\
\hline 1. & Adeno carcinoma & 5 & 1.80 \\
\hline \multirow[t]{2}{*}{2.} & Adenosquamous carcinoma & 2 & 0.72 \\
\hline & Total & 277 & 100 \\
\hline
\end{tabular}

high incidence of severe hepatocellular tumours in aged animals. $^{4,5}$

Immunologically and genetically, $H$. hepaticus closely resembles H.pylori. H. hepaticus is a gram negative, microaerobic bacterium which grows at $37^{\circ} \mathrm{C}$. It is a motile bacteria, 0.2-0.2 $\mu \mathrm{m}$ in diameter, $1.5-5 \mu \mathrm{m}$ long with curved to spiral shape which show positivity with urease, catalase and oxidase. ${ }^{6}$ This study was done to investigate whether Helicobacter species possess a causative potential for human hepatocellular disease, especially for hepatobiliary carcinogenesis. Kenzo F et al ${ }^{7}$ collected samples of bile and hepatobiliary tissue from 19 patients with hepatocellular cancer and 19 patients with benign biliary diseases which were subjected to PCR analyses for the detection of Helicobacter DNA's. They found that Helicobacter DNAs were positive in 10 of the 19 patients with hepatobiliary cancer.

\section{MATERIALS AND METHODS}

This was a retrospective study done in the department of pathology, Kathmandu Medical College for a period of 1 year, June 2007 to July 2008. A total of 277 cases were included in this study.

All the cholecystectomy specimens clinically diagnosed as chronic cholecystitis were included in the study.

The resected formalin fixed gall bladder specimen was received in the histopathology department of Kathmandu Medical College, Kathmandu. The specimens were processed and sectioned. Two slides were stained with routine haematoxylin and eosin (HE) stain. Microscopic examination was done to assess the type of inflammation, infiltrate, and presence of fibrosis, cholesterosis, metaplasia, tumor or tumor-like lesion. Two slides were stained with Warthin Silver Starry Stain to demonstrate H.hepaticus. The prepared slides were observed under oil immersion for the identification of the bacteria.

\section{RESULTS}

Amongst the 277 cases, 270 cases (97.4\%) were diagnosed as chronic cholecystitis and 7 cases $(2.5 \%)$ were diagnosed as gallbladder carcinoma. Detail diagnosis are shown in Table 1. All the cases diagnosed as gallbladder carcinoma was of adenocarcinoma (fig.1) except a single case of adenosquamous carcinoma. Fifty three out of the 277 cases (19\%) showed positivity in Warthin Starry Silver stain (fig.2) whereas 224 cases (89\%) were negative for Warthin Starry Silver stain. Out of the 7 cases diagnosed as gallbladder carcinoma, 5 cases were found to be positive for Warthin Starry Silver stain.

\section{DISCUSSION}

Chronic cholecystitis due to cholelithiasis is the most common surgical disorder and accounts for an important part of health care expenditure. ${ }^{1}$

Cholelithiasis produces diverse histolopathological changes in the gallbladder mucosa namely acute inflammation, chronic inflammation, glandular hyperplasia, granulomatous inflammation, cholesterolosis, metaplasia, dysplasia and carcinoma. ${ }^{8,9}$

Histopathological features of chronic cholecystitis showed variation with the studies in different parts of the world. Classic chronic cholecystitis was found by Tyagi et al ${ }^{10}$ in $50.8 \%$, Barcia $^{11}$ in $59 \%$ and Khomeriki et $\mathrm{al}^{12}$ in $23 \%$ of the cases in their respective study. In the present study, 59.64\% 


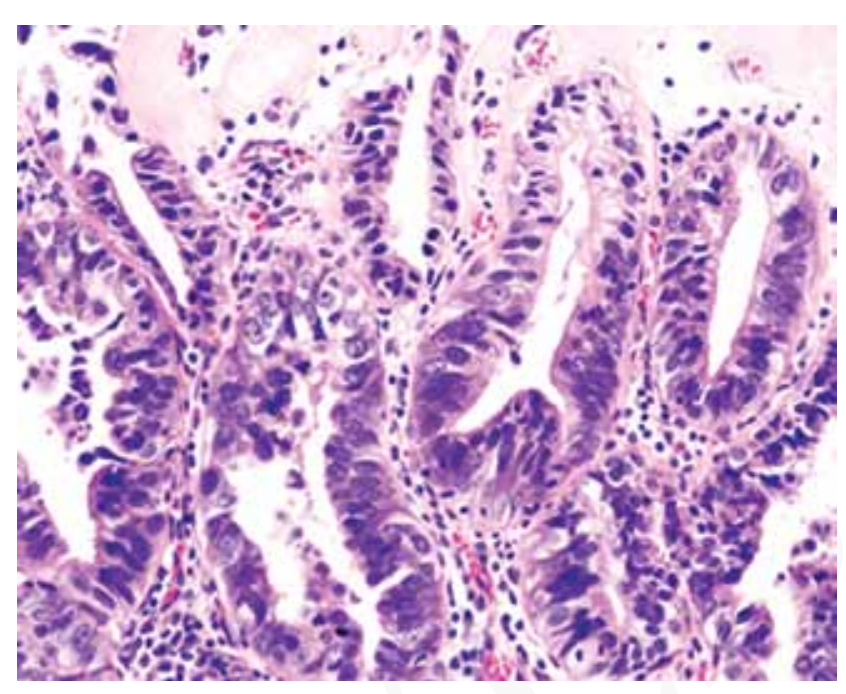

Figure 1: Adenocarcinoma of the gallbladder (HE stain, X40)

had classic chronic cholecystitis. Associated features with cholecystitis like acute on chronic cholecystitis was found in $13.2 \%$ by Tyagi et $\mathrm{al}^{10}, 16 \%$ by $\mathrm{Barcia}^{11}$. A slightly lower incidence of associated features with cholecystitis was found in our study $(8.21 \%)$.

There was significant variation in the incidence of cholesterosis in different studies. In a study by Baibekov et $\mathrm{al}^{13}$, an incidence of $3.4 \%$ was reported. Another study by Khomeriki et $\mathrm{al}^{12}$ showed an incidence of $49.9 \%$. In the present study, cholesterosis was found in $16.07 \%$. The difference may be due to the variation in the cholesterol level in the patients in different parts of the world. It may also be due to the time of detection of the pathology in the gallbladder specimens as cholesterosis may disappear if there is severe chronic inflammation in the gallbladder. Hence, incidence cannot be co-related correctly. ${ }^{12}$

In the present study, xanthogranulomatous cholecystitis was seen in $1 \%$ of the cases which is similar to other studies of Lehmann et $\mathrm{al}^{14}(1.8 \%)$ and Guzman- Valdivia ${ }^{15}(1.6 \%)$. In contrast to the present study, higher incidences have been found by Rao et $\mathrm{al}^{16}$ and Solanski et $\mathrm{al}^{17}$ showing $13.2 \%$ and $10.8 \%$ cases of xanthogranulomatous cholecystitis respectively.

The incidence of gall bladder carcinoma in our study was found to be $2.5 \%$. Similar incidence was found in other study. ${ }^{18}$ The reported incidence of carcinoma of the gallbladder in USA is $1-2.5$ per 100,000 people. ${ }^{19}$ It is the most common biliary tract malignancy comprising $4.4 \%$ of all malignancies in and around the Varanasi region of India. ${ }^{20,21}$

H.hepaticus was found in $53(19.14 \%)$ of the cases in histological sections observed by Warthin Starry Silver Stain. Pradhan et $\mathrm{al}^{22}$ detected $82 \%$ positive cases of $\mathrm{H}$.

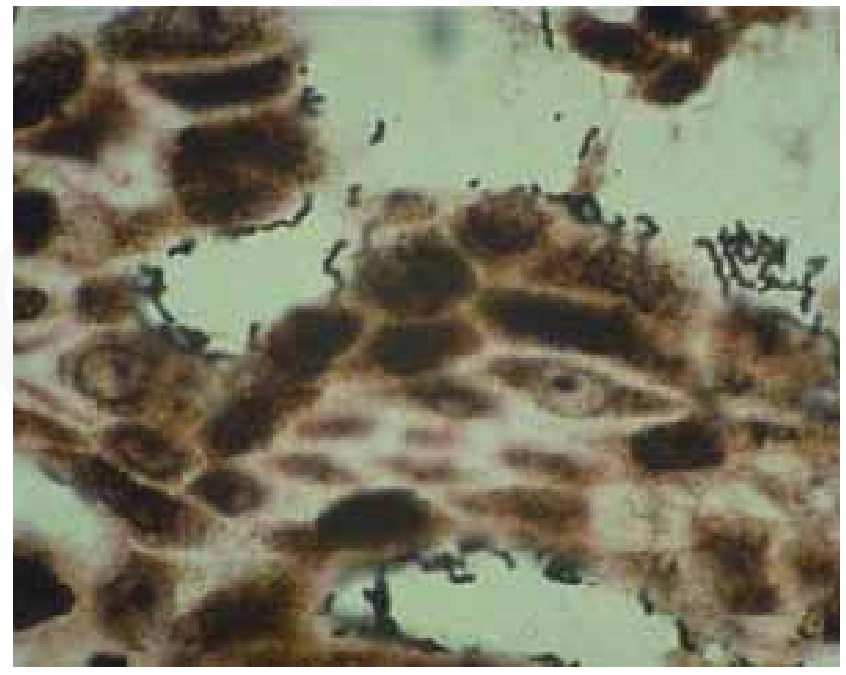

Figure 2: Curved comma shaped bacilli (Warthin Starry silver stain, X100)

hepaticus in the gallbladder mucosal folds. H.hepaticus was found in $71.42 \%$ ( 5 cases) of malignant cases of gallbladder and absent in $28.58 \%$ ( 2 cases) of carcinoma gallbladder associated with gall stone.

There seems to be some association of Helicobacter hepaticus with gall bladder carcinoma. Among the seven cases of carcinoma in this study, 5 cases showed positivity $(71.42 \%)$ to helicobacter hepaticus in the gall bladder mucosal fold. Kobayashi et $\mathrm{al}^{23}$ and Pradhan et $\mathrm{a}^{22}$ have shown higher incidence of Helicobacter species in hepatobiliary malignancy with $52.6 \%, 85 \%$ and $80 \%$ respectively. The variation in the method of detection and the number of cases studied may be responsible for these contrasting results.

H.hepaticus itself acts as risk factor for pathogenesis of carcinoma gallbladder or it acts as a nidus for the formation of gallstone that ultimately leads to malignancy has not been studied. In a study done by James GF et al in Chile 7 , 39.13\% of gallbladder tissues were found to have H.hepaticus infection.

\section{CONCLUSION}

The role of $\mathrm{H}$. hepaticus infection as a nidus for formation of gallstone that ultimately leads to malignancy is controversial and its sole dominant role in the pathogenesis of carcinoma is yet to be determined.

\section{REFERENCES}

1. Beckingham IJ. ABC of disease of liver, pancreases and biliary system. BMJ 2001;322:91-4.

2. Crawford, JM. The liver and the biliary tract infection. RS Cohtran, V Kumar and S.L. Robbins. Pathologic basis of disease, 5th ed. Philadelphia: W.B. Saunders Company; 2006. pp883-96. 
3. Swidsinski A, Lee SP. The role of bacteria in gallstone pathogenesis. Front Biosci 2001;1:93-103.

4. Lee A, Faulding Florey Medal nomination; NHMRC 1998. Annual Report; pp 20-22.

5. Kawaguchi M. Bacteria closely resembling Helicobacter pylori detected immunologically and genetically in resected gallbladder mucosa. J Gastroenterol 1996;31:294-8.

6. Ward JM, Fox JG, Anver MR et al. Chronic active hepatitis and associated liver tumors in mice caused by a persistent bacterial infection with a novel Helicobacter species. J Natl Cancer Instit. 1992;86:1222-7.

7. Kenzo F, Tamotsu K, Yoshitsugu T et al. Comparative analysis of Helicobacter DNA's and biliary pathology in patients with and without hepatobiliary cancer, Carcinogenesis, 2002;23: 1927.

8. Cherviak PI, Deineka SV. Morphological characteristics of calculous cholecystitis. Klin Khir 1983;9:23-4.

9. Siliutin VG, Kulikova NG. Clinico-anatomical characteristics of various forms of chronic calculous cholecystitis. Khirurgiia (Mosk). 1989;1:33-7.

10. Tyagi N, Maheshwari V, Ashraf Sm, Sahoo P. Morphological changes in diseased gallbladder; a study of 415 cholecystectomies at Aligarh, J Indian Med Assoc 1992;90:178-81.

11. Barcia JJ. Histologic analysis of chronic inflammatory patterns in 95 cases of the gallbladder; diagnostic criteria for reporting cholecystitis. Ann Diagn Pathol 2001;7:147-53.

12. Khumeriki SG, Orlova IN, Iichenko AA et al. Quantitative analysis of morphological manifestations of cholesterosis and concomitant pathology of the gallbladder. Arch Pathol 2004;66:12-5.
13. Baibekov I, Vorozheikin VM, Cholesterosis of the gallbladder. Arch Pathol 1985;47:44-6.

14. Lehmann L, Kraus K. Xanthogranulomatous Cholecystitis: differentiation from associated gallbladder carcinoma. Trop Gastroenterol 2005;26:31-3.

15. Guzman-Valdivia G. Xanthogranulomatous Cholecystitis: 15 years experience . World J Surg. 2004;28:254-7.

16. Rao I, Araya JC, Villaseca M et al. Preneoplastic lesions and gallbladder cancer; an estimate of the period required for progression. Gastroenterology 2005;11:232-6.

17. Solanki RL, Arora HL, Gaur SK, Anand VK, Gupta R. Xanthogranulomatous Cholecystitis: a clinicopathological study of 21 cases. Indian J Pathol. Microbiol 2004;32:256-60.

18. Lam CR. Present status of carcinoma of the gallbladder, study of 34 clinical cases. Ann Surg 1940;111:403-10.

19. Brudette WJ. Carcinoma of the gallbladder. Ann Surg 1957;145:83247.

20. Shukla VK, Khandelwal C, Roy SK et al. Primary carcinoma of the gallbladder. A review of 16 years period at University Hospital. J Surg Oncol 1985;28:32-5.

21. Pandey M, Pathak AK, Singh S et al. Carcinoma of the gallbladder is a retrospective review of 99 cases. Dig Dis Sci 2001;46:1145-51.

22. Pradhan SB, Dali S. Relation of Helicobacter hepaticus and gallbladder neoplasm. KUMJ 2004;2:331-5.

23. Kobayashi T, Harada K, Miwa K, Nakanuma Y. Helicobacter genus DNA fragments are commonly detectable in bile from patients with extra hepatic biliary disease and associated with their pathogenesis. Dig Dis Sci 2005;50: 862-7. 